\title{
Helicobacter pylori infection in children
}

\author{
Shaman Rajindrajith ${ }^{1}$, Niranga Manjuri Devanarayana ${ }^{2}$, H Janaka de Silva ${ }^{3}$
}

Sri Lanka Journal of Child health, 2009; 38: 86-88

(Key words: Helicobacter pylori, stool antigen test)

Helicobacter pylori (H. pylori) infection is one of the common gastrointestinal infections in humans. It is now clear that $H$. pylori infection is acquired during childhood. The prevalence of $H$. pylori infection in children in developed countries ranges from $4.8 \%$ to $12.2 \%{ }^{1,2}$. In developing countries the prevalence rates are much higher and vary from $15 \%$ in Gambian children aged less than 20 months ${ }^{3}$ to $69.7 \%$ in preschoolers in Brazil ${ }^{4}$. An age related increase of prevalence, irrespective of the economic status of the country, has been observed by several independent studies across the world ${ }^{2,3}$

H. pylori was first reported in Sri Lanka in 1992 in $67 \%$ of adult patients with duodenitis and $8 \%$ of adults with non-ulcer dyspepsia ${ }^{5}$. Six years later, $H$. Pylori was isolated from an 80 year old man with an antral gastric ulcer and atropic gastritis ${ }^{6}$. A subsequent study has shown $H$. pylori infection in $2.9 \%$ of adult patients with functional dyspepsia ${ }^{7}$. Two studies done among Sri Lankan school children have reported prevalence of $6.5 \%{ }^{8}$ and $5 \%$ by using a stool antigen test and $27.7 \%$ by detection of salivary ( $\mathrm{IgG})$ antibodies $^{8}$. The reason for this relatively lower prevalence of $H$. pylori in Sri Lanka, compared to other developing countries, is multifactorial. Easily accessible free health care system, reasonably good housing and sanitary facilities and availability of safe drinking water are possible reasons. Furthermore, almost all studies done in developing countries have used serological tests to find the prevalence of $H$. pylori infection. Serological positivity does not necessarily indicate active infection, and can sometimes be a marker of a past infection. Only children having acute infection will shed antigen in their stools. Therefore, the prevalence rate using a stool antigen test may be lower compared to seroprevalence.

The main predisposing factor for $H$. pylori infection in children seems to be low socioeconomic status. However, McCallion et al. suggest that with regard to acquisition of infection, social class was acting as a proxy measure for

${ }^{1}$ Department of Paediatrics, ${ }^{2}$ Department of Physiology, ${ }^{3}$ Department of Medicine, Faculty of Medicine, University of Kelaniya, Ragama, Sri Lanka. conditions and practices within the household that increase the transmission of organism from infected to uninfected individuals ${ }^{10}$.

The human stomach is the primary natural reservoir of H. pylori. Person-to-person spread appears to be the most likely mode of transmission. The possible routes are faeco-oral, oral-oral and gastro-oral. Several investigators have isolated viable $H$. pylori from human faeces suggesting the potential for faeco-oral transmission ${ }^{11}$. Oral-oral transmission was suggested after isolation of $H$. pylori from dental plaques and saliva ${ }^{12}$. The possibility of gastro-oral transmission was postulated after the organism was cultured from the vomitus of an infected child ${ }^{13}$. However, further research in this area is needed as the current knowledge on exact modes of transmission is far from conclusive.

Diagnosis is based on invasive and non invasive tests. A variety of invasive tests are used in the diagnosis of $H$. pylori. They include histological examination of gastric tissue, bacterial culture, rapid urease test, and polymerase chain reaction (PCR). Invasive tests need upper gastrointestinal endoscopy (UGIE) and gastric biopsy. Endoscopy and biopsy cannot be justified in children unless one wishes to isolate the organism for antibiotic sensitivity testing or there is a clear clinical indication for UGIE.

Histology demonstrates inflammation (gastritis) and $H$. pylori itself, if plentiful. Cultures are only performed in research settings and suspected drug resistance. The ability of the organism to split urea by the enzyme urease is used to identify $H$. pylori in biopsy specimens using the rapid urease test. The accuracy of this test is dependent on the number of tissue specimens tested, the location from which the biopsy was obtained, bacterial load, previous use of antibiotics and proton pump inhibitors, as well as the prevalence of infection in the community ${ }^{14}$.

Non-invasive tests for $H$. pylori include measurement of Helicobacter antibodies, urea breath test and stool antigen test. H. pylori infection exerts an immunological response in the body. The presence of $H$. pylori antibodies does not always denote active infection. IgG antibodies can be 
measured in serum and saliva. Currently serological tests are not recommended for the diagnosis of $H$. pylori infection in children owing to their varying sensitivities and specificities in the paediatric age group ${ }^{15}$. The ${ }^{13} \mathrm{C}$ urea breath test is a safe method for diagnosing $H$. pylori infection in children. The sensitivity, specificity, positive predictive value and negative predictive values of the ${ }^{13} \mathrm{C}$ urea breath test are approximately $100 \%$, $97 \%, 98 \%$ and $100 \%$ in children ${ }^{16}$. H. pylori stool antigen test is another safe diagnostic test. The sensitivity, specificity, positive predictive value and negative predictive value of this test in children are approximately $96 \%, 95 \%, 95 \%$ and $97 \%$, and this has become the recommended test for diagnosis of $H$. pylori infection in paediatric patients ${ }^{16}$.

It is important to keep in mind that testing children for $H$. pylori infection is only recommended in conditions that have a definite association with $H$. pylori. Definitive associations are gastritis, peptic ulcer disease, gastric adenocarcinoma, gastric nonHodgkin lymphoma and gastric MALToma while the doubtful associations are gastro-oesophageal reflux disease, iron deficiency anaemia, growth faltering, recurrent abdominal pain and functional dyspepsia ${ }^{17}$. The tests used should have the ability to diagnose active infection. These include demonstration of the organism by histology or culture from endoscopic biopsy, urea breath test or stool antigen test ${ }^{15}$.

Conditions that require treatment for $H$. pylori infection include endoscopically proven gastric or duodenal ulcer, histological evidence of gastric MALToma and pathologically proven gastric metaplasia in atrophic gastritis ${ }^{15}$. Treatment is not recommended in children with recurrent abdominal pain, and functional dyspepsia. It is also important to note that there is no evidence that treatment is beneficial in children with unexplained short stature, or in those that are at risk of infection (e.g. asymptomatic children who have a family member with either peptic ulcer or gastric cancer $)^{15}$.

Treatment is intended to eradicate $H$. pylori from the gastro-duodenal mucosa. It is vital to accomplish complete eradication as even a small residual colony will lead to re-colonization and reinfection. Under treatment also leads to drug resistance $^{15}$. It is imperative that treatment is reserved for those patients who will benefit from eradication, and when offered, complete courses are given, and appropriate protocols that account for common local resistance patterns are followed. Evidence based data regarding anti- $H$. pylori treatment in children is not widely available. Most are open-labelled, case series and uncontrolled, anecdotal observations that do not meet the minimum criteria for determining efficacy ${ }^{15}$. Current treatment strategies have been developed primarily by using data from adults. Most of the treatment options have not been formally tested on children in developing countries, where the prevalence is high. The standard "triple therapy" used in children includes 2 weeks treatment with amoxicillin, clarithromycin and a proton pump inhibitor (omeprazole or lansoprazole) or clarithromycin, metronidazole and a proton pump inhibitor. As a second a line option, a combination of bismuth subsalicylate, amoxicillin and metronidazole for 2 weeks has been used successfully ${ }^{18}$. "Quadruple therapy", sequential therapy and salvage regimes with other antibiotics (rifabutin, levofloxacin and furozolidone) have not been tested in children up to now. It is also important that eradication is confirmed with a urea breath test or faecal antigen test 8 weeks after treatment. Failure to eradicate is an indication to use second line drugs. Repeated treatment failure is a clear indication to perform culture and antibiotic sensitivity of the organism ${ }^{19}$.

\section{References}

1. Rothenbacher D, Bode G, Berg G, Gommel R, Gonser T, Alder $\mathrm{G}$, et al. Prevalence and determinants of Helicobacter pylori infection in preschool children: a population based study from Germany. Int J Epidemiol 1998; 27(1): 135-41.

2. Opekun AR, Gilger MA, Denyes SM, Nirken MH, Philip SP, Osato MS, et al. Helicobacter pylori infection in children of Texas. J Pediatr Gastroenterol Nutr 2000; 31(4): 405-10.

3. Sullivan PB, Thomas JE, Wight DG, Neale G, Eastham EJ, Corrah T, et al. Helicobacter pylori in Gambian children with chronic diarrhoea and malnutrition. Arch Dis Child 1990; 65(2): 189-91.

4. Rocha GA, Rocha AM, Silva LD, Santos A, Bocewicz AC, Queiroz Rd Rde M, et al. Transmission of Helicobacter pylori infection in families of preschool-aged children from Minas Gerais, Brazil. Trop Med Int Health 2003; 8(11): 987-91.

5. Fernando D. Helicobacter pylori and peptic ulcer disease in Sri Lanka. Cey Med $J$ 1992; 37(1): 15-7. 
6. Chandrasiri P, Wickramasinghe RS, Fernando D, Jayasena R. The first isolation of Helicobacter pylori from gastric biopsy specimens in Sri Lanka. Cey Med J 1998; 43 (2): 119-20.

7. de Silva M. Prevalence of Helicobacter pylori infection in patients with functional dyspepsia. Cey Med J 1999; 44 (3): 118-9.

8. Fernando N, Perera N, Vaira D, Holton J. Helicobacter pylori in school children from the Western province of Sri Lanka. Helicobacter 2001; 6(2): 169-74.

9. Devanarayana NM, de Silva DGH, de Silva HJ. Aetiology of recurrent abdominal pain in a cohort of Sri Lankan children. J Paediatr Child Health 2008; 44:195-200.

10. McCallion WA, Murray LJ, Bailie AG, Dalzell AM, O'Reilly DP, Bamford KB. Helicobacter pylori in children: relation with current household living conditions. Gut 1996; 39(1): 18-21.

11. Thomas JE, Gibson GR, Darboe MK, Dale A, Weaver LT. Isolation of Helicobacter pylori from human faeces. Lancet 1992; 340(8829): 1194-5.

12. Goosen C, Theron J, Ntsala M, Maree FF, Olckers A, Botha SJ, et al. Evaluation of a novel heminested PCR assay based on the phosphoglucosamine mutase gene for detection of Helicobacter pylori in saliva and dental plaque. J Clin Microbiol 2002; 40(1): 205-9.

13. Leung WK, Siu KL, Kwok CK, Chan SY, Sung R, Sung JJ. Isolation of Helicobacter pylori from vomitus of children and its implication in gastro-oral transmission. Am J Gastroenterol 1999; 94(10): 2881- 4.
14. Dunn BE, Cohen H, Blaser MJ. Helicobacter pylori. Clin Microbiol Rev 1997; 10(4): 720-41.

15. Gold BD, Colletti RB, Abbott M, Czinn S, Elitsur Y, Hassall E, et al. Helicobacter pylori infection in children: Recommendation for diagnosis and treatment. J Pediatr Gastroenterol Nutr 2000; 31(5): 490-7.

16. Hino B, Eliakim R, Levine A, Sprecher H, Berkowitz D, Hartman C, et al. Comparison of invasive and non-invasive tests for diagnosis and monitoring of Helicobacter pylori infection in children. $J$ Pediatr Gastroenterol Nutr 2004; 39(5): 519-23.

17. Sherman P, Czinn S, Drumm B, Gottrand F, Kawakami E, Madrazo A, et al. Helicobacter pylori infection in children and adolescents: Working group report of the First World Congress of Paediatric Gastroenterology, Hepatology and Nutrition. J Pediatr Gastroenterol Nutr 2002; 35(Supplement 2): S128-S133.

18. Campbell DI, Thomas JE. Helicobacter pylori infection in paediatric practice. Arch Dis Child (Education and Practice) 2005; 90: ep25-ep30.

19. Khurana R, Fischbach L, Chiba N, Van Zanten SV, Sherman PM, George BA, et al. Meta-analysis: Helicobacter pylori eradication treatment efficacy in children. Aliment Pharmacol Ther. 2007; 25(5): 523-36. 